\title{
Characteristics of monsoon low level jet (MLLJ) as an index of monsoon activity
}

\author{
N V Sam and K P R Vittal MuRty* \\ Centre for Atmospheric Sciences, Indian Institute of Technology, Delhi, Hauz Khas, \\ New Delhi 110 016, India \\ e-mail: nelson@cas.iitd.ernet.in \\ *Department of Meteorology and Oceanography, Andhra University, Visakhapatnam 530 003, India.
}

Temperature and wind data are used to describe variation in the strength of the Monsoon Low Level Jet (MLLJ) from an active phase of the monsoon to a break phase. Also estimated are the characteristics of turbulence above and below MLLJ.

\section{Introduction}

P. V. Joseph and P. L. Raman (IJMG 1966) pointed out the existence of a low-level jet or the Monsoon Low Level Jet (MLLJ) stream over peninsular India. They have investigated the occurrence of significant low-level wind maximum in the vertical and had defined it in accordance with the following criteria following Fay (1958):

- A maximum wind speed should exist below $6 \mathrm{~km}$.

- The wind speed should increase and then decrease with height; both through at least $10 \mathrm{kts}$ without more than 40 degrees change in the wind direction.

In this paper we have studied the activity of the monsoon with respect to MLLJ for two years, a bad monsoon year (1965) and a normal monsoon year (1966). Our aim was to see the influence of MLLJ during the active monsoon period and a break monsoon period.

\section{Data and analysis}

Wind and temperature data were taken from the Indian Daily Weather Report (IDWR), for a twoyear period 1965, 1966, for the months June and July. The heights (vertical levels) for which the data was taken are $0.9,1.5,2.1,3.0,4.5$ and $5.4 \mathrm{~km}$ a.s.l. The stations, which were studied over the peninsula, are namely Nagpur, Bombay, Trivandrum, Madras and Visakhapatnam.

The profiles of the wind speed in the vertical were drawn for active and break monsoon period. Approximately, 40 knots was found to be the speed that most frequently occurred during the active phase of monsoon. Maximum speeds obtained were of the order of 50 knots. An analysis of height most favoured by the wind maximum is $2.0 \mathrm{~km}$ a.s.l. In general it is found that vertical wind shears are higher below the wind speed maximum than above it. A shear in wind always leads to turbulence and thus turbulence related to MLLJ was studied for the active and break phase of the monsoon.

In view of the importance of atmospheric stability, which partly controls the rate of dispersion and mixing of effluents, discharged into the atmosphere, the simple Budyko's index of turbulence $\left(\Delta T / u^{2}\right)$ was computed for various heights and stations. $\Delta T$ is the difference in temperature between two layers and $\mathbf{u}$ is the mean wind in that layer.

\section{Results and discussion}

During the active phase of monsoon the MLLJ shows a core speed of 55 knots and during the break phase of monsoon the core is less than 10 knots. From figure $1(\mathrm{a}-\mathrm{d})$, we see how the vertical profile

Keywords. Monsoon Low Level Jet (MLLJ); turbulence; wind shear. 


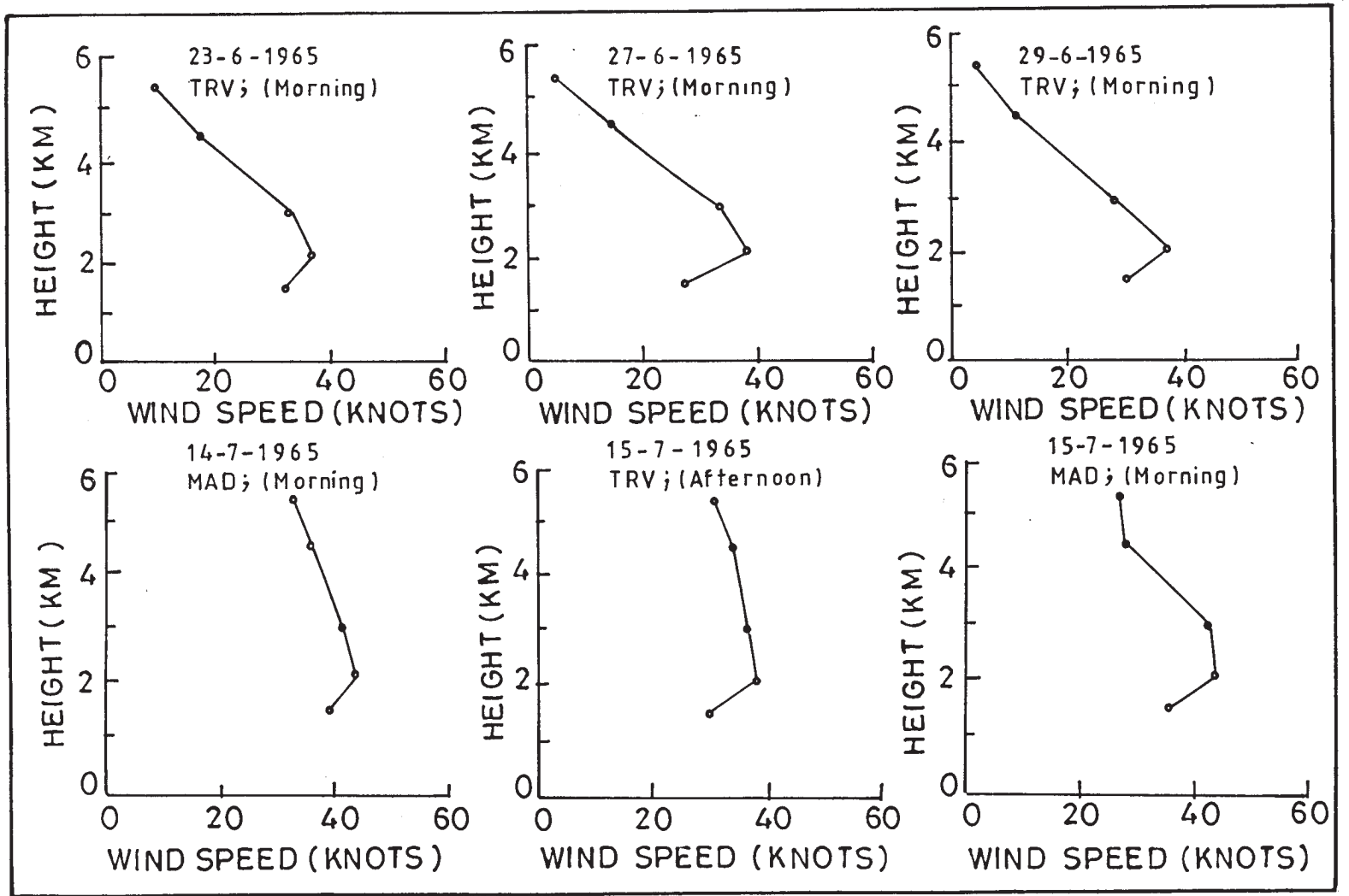

Figure 1(a). Typical vertical wind speed profiles for some cases in the active phase of monsoon in the year 1965 .

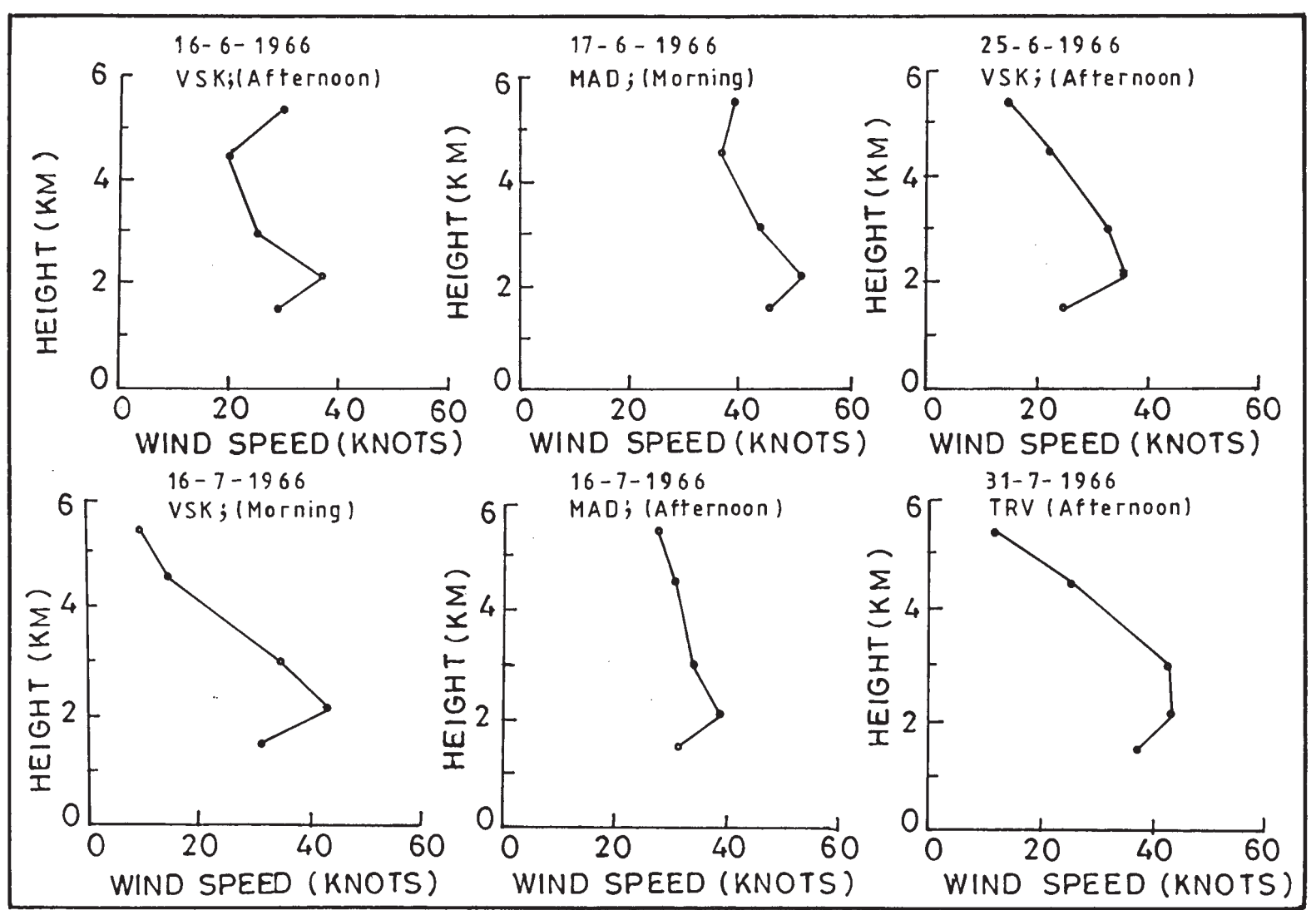

Figure 1(b). Typical vertical wind speed profiles for some cases in the active phase of monsoon in the year 1966. 


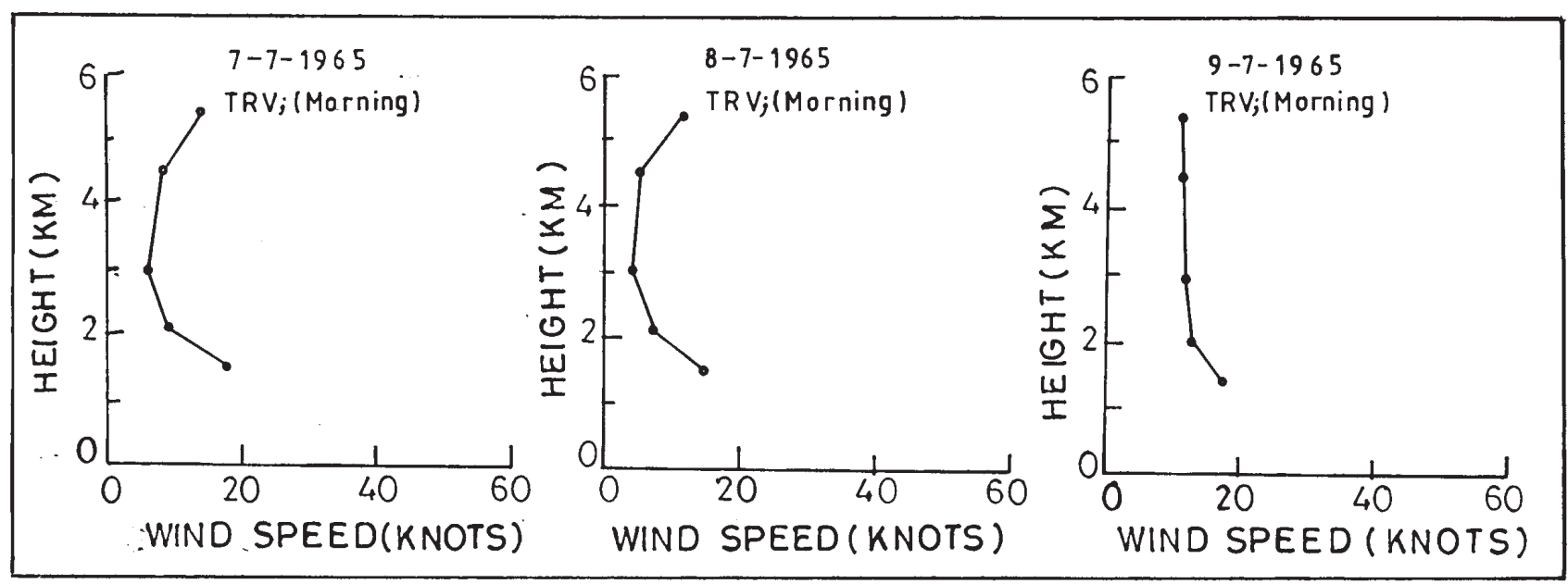

Figure 1(c). Typical vertical wind speed profiles for some cases in the break phase of monsoon in the year 1965 .

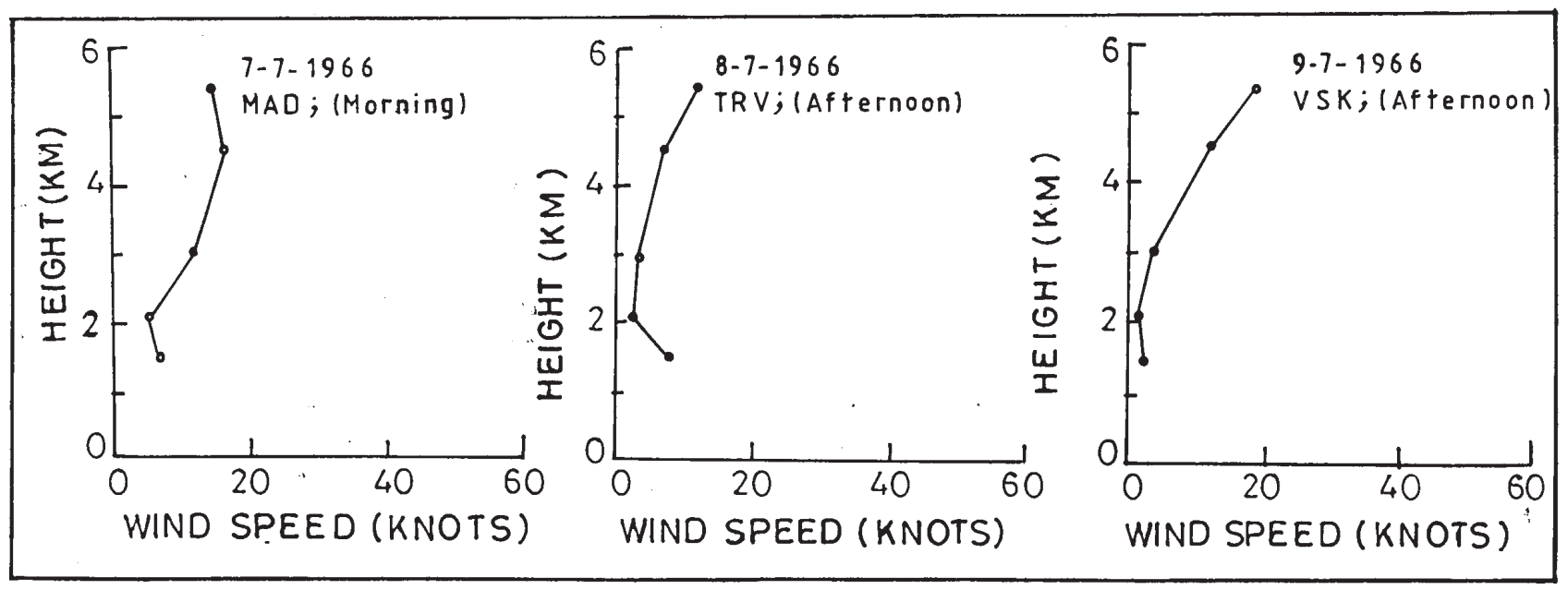

Figure 1(d). Typical vertical wind speed profiles for some cases in the break phase of monsoon in the year 1966.

Table 1(a). Turbulence index for the active phase of monsoon in the year 1965.

\begin{tabular}{lccccc}
\hline \multicolumn{1}{c}{$\begin{array}{c}\text { Height a.s.l } \\
\text { Date km }\end{array}$} & $0.9-1.5$ & $1.5-2.1$ & $2.1-3.0$ & $3.0-4.5$ & $4.5-5.4$ \\
\hline $\begin{array}{l}\text { Station } \\
\text { Trivandrum (Morning) }\end{array}$ & 0.001 & 0.003 & 0.01 & 0.02 & -0.52 \\
\hline $\begin{array}{l}27-06-1965 \\
\text { Trivandrum (Morning) }\end{array}$ & 0.02 & 0.002 & 0.004 & 0.03 & -2.24 \\
\hline $\begin{array}{l}29-06-1965 \\
\text { Trivandrum (Morning) }\end{array}$ & 0.003 & 0.002 & 0.01 & 0.06 & -2.54 \\
\hline $\begin{array}{l}\text { 14-07-1965 } \\
\text { Madras (Morning) }\end{array}$ & 0.002 & 0.002 & 0.03 & 0.01 & -0.05 \\
\hline $\begin{array}{l}15-07-1965 \\
\text { Trivandrum (Morning) }\end{array}$ & 0.004 & 0.002 & 0.003 & 0.007 & -0.059 \\
\hline $\begin{array}{l}15-07-1965 \\
\text { Madras (Morning) }\end{array}$ & 0.003 & 0.001 & 0.003 & 0.01 & -0.07 \\
\hline
\end{tabular}


Table 1(b). Turbulence index for the break phase of monsoon in the year 1965.

\begin{tabular}{|c|c|c|c|c|c|}
\hline Date $\underbrace{\substack{\text { Height a.s.l } \\
\text { in km }}}_{\text {Station }}$ & $0.9-1.5$ & $1.5-2.1$ & $2.1-3.0$ & $3.0-4.5$ & $4.5-5.4$ \\
\hline $\begin{array}{l}\text { 07-07-1965 } \\
\text { Trivandrum (Morning) }\end{array}$ & 0.006 & 0.022 & 0.186 & 0.104 & -0.27 \\
\hline $\begin{array}{l}08-07-1965 \\
\text { Trivandrum (Morning) }\end{array}$ & -0.001 & 0.071 & 0.370 & -1.471 & -0.045 \\
\hline $\begin{array}{l}09-07-1965 \\
\text { Madras (Morning) }\end{array}$ & 0.01 & 0.03 & 0.04 & 0.06 & -0.43 \\
\hline
\end{tabular}

Table 2(a). Turbulence index for the active phase of monsoon in the year 1966.

\begin{tabular}{|c|c|c|c|c|c|}
\hline Date $\underbrace{\substack{\text { Height a.s.l } \\
\text { in km }}}_{\text {Station }}$ & $0.9-1.5$ & $1.5-2.1$ & $2.1-3.0$ & $3.0-4.5$ & $4.5-5.4$ \\
\hline $\begin{array}{l}\text { 16-06-1966 } \\
\text { Visakhapatnam (Afternoon) }\end{array}$ & 0.002 & 0.003 & 0.012 & 0.02 & -0.05 \\
\hline $\begin{array}{l}\text { 17-06-1966 } \\
\text { Madras (Morning) }\end{array}$ & 0.001 & 0.006 & 0.003 & 0.005 & -0.03 \\
\hline $\begin{array}{l}25-06-1966 \\
\text { Visakhapatnam (Afternoon) }\end{array}$ & 0.007 & 0.002 & 0.007 & 0.014 & -0.23 \\
\hline $\begin{array}{l}\text { 16-07-1966 } \\
\text { Visakhapatnam (Morning) }\end{array}$ & 0.003 & 0.001 & 0.005 & 0.02 & -0.61 \\
\hline $\begin{array}{l}\text { 16-07-1966 } \\
\text { Madras (Afternoon) }\end{array}$ & 0.004 & 0.003 & 0.004 & 0.01 & -0.07 \\
\hline $\begin{array}{l}\text { 31-07-1966 } \\
\text { Trivandrum (Afternoon) }\end{array}$ & 0.002 & 0.002 & 0.003 & 0.009 & -0.35 \\
\hline
\end{tabular}

Table 2(b). Turbulence index for the break phase of monsoon in the year 1966.

\begin{tabular}{lcccccc}
\hline $\begin{array}{c}\text { Height a.s.l } \\
\text { in km }\end{array}$ & $0.9-1.5$ & $1.5-2.1$ & $2.1-3.0$ & $3.0-4.5$ & $4.5-5.4$ \\
$\begin{array}{l}\text { Station } \\
\text { Time }\end{array}$ & & & & & \\
$\begin{array}{l}\text { Madras (Morning) } \\
\text { 08-07-1966 }\end{array}$ & 0.06 & 0.09 & 0.07 & 0.05 & -0.25 \\
$\begin{array}{l}\text { Trivandrum (Morning) } \\
\text { 09-07-1966 }\end{array}$ & 0.15 & 0.24 & 0.49 & 0.10 & -0.38 \\
Visakhapatnam (Morning) & 0.32 & 1.33 & 0.45 & 0.04 & -0.14 \\
\hline
\end{tabular}

of MLLJ varies from an active to a break monsoon period.

A careful examination of the significant wind maximum for these two years showed that when Trivandrum and Madras show significant wind maximum of large wind speeds, Bombay and Nagpur do not show such maximums. Wind maximum of large wind speeds are also found in Visakhapatnam but smaller than Trivandrum and Madras.
This could be due to a low-level jet stream, which moves from one latitude to another. Higher vertical wind shears are found below the level of wind maximum than above it. This is particularly so when the jet core is around $2 \mathrm{~km}$.

From Budyko's index of turbulence it was found that $\Delta T / u^{2}$, was less for July, than June, which again clearly shows that the lesser Budyko's index of turbulence, the more is the turbulence indicating 
a strong jet core and high vertical wind shear. Analyzing the two levels viz., " $0.9-1.5$ " $\mathrm{km}$ and "1.52.1 " km, Budyko's index was found to be less here compared to all the other levels. Also among these two levels, the index was less in "1.5-2.1" km level than in " $0.9-1.5 " \mathrm{~km}$. This indicates that turbulence is larger below the jet core than above it. Turbulence index for some typical days in the active and break phase of monsoon of the years 1965 and 1966 are given in table $1(\mathrm{a}, \mathrm{b})$ and table $2(\mathrm{a}, \mathrm{b})$.

This jet stream is expected to have a good effect on the distribution of rainfall with respect to its axis and is therefore important in the forecasting of South West monsoon rainfall. The present work is a preliminary one. Various other aspects of MLLJ are being studied which will be communicated in future.

\section{References}

Fay R 1958 Bull. Amer. Meteor. Soc. 39 360-362

Joseph P V and Raman P L 1966 Existence of low-level westerly jet stream over peninsular India during July; Indian J. Meteorol and Geophys. 407-410 